\title{
Saúde, Segurança e Meio ambiente: Análise Preliminar de Riscos em atividades que fazem o uso da água em Cozinha Hospitalar
}

\section{Health, Safety and Environment: Preliminary Risk Analysis on activities involving water use in Hospital Kitchen}

\author{
${ }^{1}$ Thaiza Fernanda Christóffoli, ${ }^{2}$ Luciane Cleonice Durante, ${ }^{3}$ Raquel Naves Blumenschein, ${ }^{4}$ Joceli Fernandes \\ Alencastro Bettini de Albuquerque Lins, ${ }^{5}$ José Vinnícius Ranieri Moreira
}

${ }^{1}$ Arquiteta e Urbanista, discente do curso de especialização em Engenharia de Segurança do Trabalho, Faculdade
de Arquitetura, Engenharia e Tecnologia, Universidade Federal de Mato Grosso, Cuiabá-MT (thaizafcbr@gmail.com)

2Doutora em Física Ambiental, docente da Faculdade de Arquitetura, Engenharia e Tecnologia, Universidade Federal de Mato Grosso, Cuiabá-MT (luciane.durante@ hotmail.com)

${ }^{3}$ Doutora em Desenvolvimento Sustentável, docente da Universidade de Brasília, Campus Darci Ribeiro, Brasília - DF (raquelblum@terra.com.br)

${ }^{4}$ Doutora em Ciências, docente da Faculdade de Enfermagem, Universidade Federal de Mato Grosso, CuiabáMT

${ }^{5}$ Discente do curso de graduação em Engenharia Civil da Faculdade de Arquitetura, Engenharia e Tecnologia, Universidade Federal de Mato Grosso, Cuiabá-MT (jvinnicius@gmail.com)

RESUMO: Este estudo teve por objetivo avaliar os riscos ocupacionais presentes nas atividades que fazem maior uso da água, em uma Unidade de Alimentação e Nutrição (UAN) hospitalar, propondo ações mitigadoras para os problemas encontrados. Utilizou-se de metodologia qualitativa e descritiva, com a realização de visitas in loco para observar a qualidade do ambiente e a execução das tarefas, além da pesquisa teórica para análise dos riscos, caracterização funcional de uma UAN hospitalar e gestão do uso racional da água. Detectaram-se problemas nas instalações, principalmente referentes ao piso e ao sistema de exaustão, sendo os agentes ambientais agravados e deixando o local em condições insatisfatórias, de acordo com as normativas vigentes. Na execução das tarefas, pode se notar que a maneira como a água é utilizada demonstra ir de acordo com as Boas Práticas, mas a forma com que a mesma é utilizada nesse ambiente de trabalho não está sendo favorável ao descarte responsável. Esta pesquisa demonstrou a necessidade de implementação de planos de gestão integrados que busquem diminuir os impactos ambientais, reduzir gastos financeiros e que possam ser revertidos em melhorias nas condições de saúde e qualidade de vida dos colaboradores das unidades de saúde.

Palavras Chave: Riscos ambientais. Biossegurança. Higienização. Reuso de água.

ABSTRACT: The aim of this study was to evaluate the occupational risks in the activities that make large use of water, in a hospital Food and Nutrition Unit (UAN), proposing mitigating actions for detected's problems. It was used qualitative and descriptive methodology, with in loco visits to observe the quality of the environment and the process, as well as theoretical research for risk analysis, functional characterization of a hospital UAN and water resource management. Problems in the installations were detected, mainly related to the floor and the exhaust system, being the environmental agents aggravated and leaving the premises in unsatisfactory conditions, according to regulations in force. In tasks execution, it was noticed that the water is used according to best practices, however, its involvement is not favorable to responsible disposal. This research demonstrated how important is to implement integrated management that seek to reduce environmental impacts, reduce financial expenses and that can be reversed in improvements on health conditions and quality of hospital's employees life.

Keywords: Environment risks. Biosafety. Sanitizing.; Water reuse.

\section{INTRODUÇÃO}

A Segurança e Saúde do Trabalho (SST) tem como essência a prevenção de riscos e proteção contra danos à saúde do trabalhador em todas as etapas do trabalho, por meio da gestão organizacional, políticas públicas e de ações físcalizadoras. Devem-se reduzir os riscos profissionais inerentes ao mínimo, tornando-os aceitáveis e justificáveis dentro do ambiente de trabalho. 
Na norma OSHAS 18001- Sistemas de gestão da segurança e da saúde do trabalho Requisitos (BSI, 2007) define-se risco como "combinação da probabilidade da ocorrência de um acontecimento perigoso ou tipo de exposição(ões) e da severidade das lesões, ferimentos ou danos para a saúde, que pode ser causada pelo acontecimento ou pela(s) exposição(ões)". Com o conceito reformulado, a DIS ISO 45001(ISO, 2016) ${ }^{1}$ traz essa situação como Riscos de Segurança e Saúde Ocupacional, mas levando em consideração que o acontecimento perigoso é relacionado ao trabalho e o risco computado somente como "efeito de incerteza".

Já para a NR 9, intitulada Programa de Prevenção de Riscos Ambientais (PPRA) (BRASIL, 1978), consideram-se "riscos ambientais os agentes físicos, químicos e biológicos existentes nos ambientes de trabalho que, em função de sua natureza, concentração ou intensidade e tempo de exposição, são capazes de causar danos à saúde do trabalhador".

Em se tratando de uma Unidade de Alimentação e Nutrição (UAN) hospitalar, é relevante a análise da organização do ambiente, dos pontos críticos existentes que podem melhorar os processos produtivos (LEHMKUHL, 1998). Araújo (2010) também destaca a importância de identificar os fatores que interferem no desempenho e na satisfação dos trabalhadores, bem como os que contribuem para os acidentes de trabalho e absenteísmo, tais como o ritmo, a jornada, as posturas e os movimentos, dentre outros.

Isosaki et al. (2011), em um estudo realizado em um serviço de nutrição de um hospital de cardiologia em São Paulo (SP), identificaram a prevalência de sintomas osteomusculares, principalmente nos membros inferiores e nos ombros, e a causa mais citada desses sintomas foi o movimento de andar e transportar cargas durante as atividades diárias $(31 \%)$, indicando como a rotina intensa, associadas às condições ambientais podem atuar nas doenças do trabalho.

Por meio de práticas de atenção à saúde do trabalhador, como ginástica laboral, realizadas em duas instituições, Ponte et al. (2014) ao elaborarem Mapa de Risco analisaram que as principais irregularidades estão no ambiente e na organização, indicando as melhores adaptações futuras para os postos de trabalho, bem como atividades de interação, sob o ponto de vista da Terapia Ocupacional.

Em uma UAN, os riscos ambientais são apresentados de forma simultânea e sinérgica e a possiblidade de ser um veículo de contaminação (caso não se utilize de práticas corretas de higiene) pode ser um fator de sobrecarga mental, exigindo que o profissional esteja apto e capacitado para tal função neste ambiente (BRASILEIRO et al., 2013).

Por se constituírem em ambientes de risco, as UAN possuem extensa normatização sobre o que devem conter e sobre as práticas do trabalho nelas executado.

A Agência Nacional de Vigilância Sanitária (ANVISA), na Resolução no 50, de 21 de fevereiro de 2002 (BRASIL, 2002), define alguns parâmetros a serem seguidos no planejamento, programação e na elaboração avaliação de projetos físicos de estabelecimentos de assistência de saúde. Para a Cozinha, referente às instalações prediais, orienta-se que tenha uma caixa de separação de gordura específica para os rejeitos das atividades da Unidade de Nutrição e Dietética (além do lactário e nutrição enteral). Com relação ao consumo de Água Fria, além da quantidade média a ser considerado referente à população, acrescenta-se para a Cozinha o consumo para preparo e cocção dos alimentos, lavagem de panelas e utensílios, louças, bandejas, talheres e carrinhos.

\footnotetext{
${ }^{1}$ A futura ISO 45001 encontra-se em fase de tramitação final e foi projetada para substituir OHSAS 18001. Ela compartilha aproximadamente 50\% da mesma linguagem de outros dois padrões ISO: a ISO 14001 e a ISO 9001. Fonte: <https://ohsonline.com/articles/2018/02/01/the-wait-for-iso-45001-is-over.aspx>.
} 
Com relação à segurança contra incêndio, indica-se a setorização e compartimentação de acordo com a população, instalações físicas e função. Assim, o Serviço de Nutrição e Dietética (Cozinha) é considerado de risco especial pela carga de incêndio que possui, sendo desta forma detalhado em separado, classificando o risco destes locais em baixo (até $20 \mathrm{~m}^{2}$ ) / médio $\left(20-200 \mathrm{~m}^{2}\right)$ e alto $\left(+200 \mathrm{~m}^{2}\right)$.

De acordo com a NR 32 (BRASIL, 2011), que se refere à Segurança e Saúde no Trabalho em Serviços de Saúde, as Cozinhas devem ser dotadas de sistemas de exaustão e outros equipamentos que reduzam a dispersão de gorduras e vapores, conforme estabelecido na NBR 14518 - Ventilação para Cozinhas Profissionais (ABNT, 2000).

Seguindo a Resolução RDC n 50/2002 (BRASIL, 2002) e seguindo as recomendações da Associação Brasileira das Empresas de Refeições Coletivas, para que se tenha um fluxo operacional contínuo na intenção de eliminar a contaminação cruzada, uma Cozinha de porte industrial, como é a hospitalar, deve, no mínimo, conter as seguintes áreas: Recepção e inspeção de alimentos e utensílios; Área para armazenamento de alimentos com temperatura ambiente controlada; Despensa/ Guarda de utensílios; Área de pré-preparo e preparo para verduras, legumes e cereais, carnes, massas e sobremesas; Cocção (dietas normais, especiais, desjejum e lanches); Recepção, lavagem e guarda de louças, bandejas e talheres; Lavagem e guarda de panelas; Área para higienização das mãos; Área para recepção, lavagem e guarda de carrinhos; Um balcão (mínimo) para distribuição de dietas (normais e especiais); Instalações Sanitárias e Vestiários e Depósito de Lixo (ABERC, 2013).

Diversos autores pesquisaram UAN e uso da água, objeto desse estudo, destacando-se aqui Kaminagakura (2005), que identificou os principais fatores que contribuem para a otimização do uso da água e o combate do desperdício envolvendo aspectos do projeto, de gestão do processo produtivo e da implantação de ações tecnológicas. As atividades que se destacaram quanto à capacidade de redução na demanda foram a higienização de louças e utensílios e o preparo de hortifrúti. Em relação à gestão, relevou-se a importância do papel do nutricionista em incorporar os aspectos da gestão da água em sua atuação, visto que programas de racionabilidade da água envolvem a continuidade de ações, não somente implantação de medidas tecnológicas.

Lima (2007) investigou como eram realizadas as atividades que envolviam o uso doméstico da água, no Hospital das Clínicas da UNICAMP, e detectou as possíveis fontes de desperdício, ligadas a essas atividades e, desta forma, pode propor ações para minimizá-las. $\mathrm{Na}$ Cozinha, efetuaram-se estimativas do volume de água desperdiçado em 11 atividades $^{2}$ e um grau mais baixo de desperdício foi encontrado somente no descongelamento da carne (e maior potencial de reuso), enquanto todas as outras lavagens, incluindo frutas, foram de alto grau. A atividade que mais consumiu água e que mais desperdiçou foi a pré-lavagem dos utensílios (bandejas, talheres, dentre outros).

O tema do uso da água tem sido abordado, atualmente, com relevância. A "Agenda 2030 para o Desenvolvimento Sustentável", documento conjunto da Organização das Nações Unidas (ONU, 2015) com mais de 150 líderes mundiais, prevê 17 Objetivos. Dentre eles está o de número seis "Água Potável e Saneamento", almejando a redução à metade a proporção de águas residuais não tratadas; aumentar substancialmente a reciclagem e reutilização segura globalmente e a eficiência do uso da água em todos os setores.

\footnotetext{
${ }^{2}$ Pré-lavagem de utensílios; lavagem de panelas grandes e palafrões; lavagem de utensílios de pequeno e médio porte; lavagem de frutas descongelamento de carne; lavagem de carnes; limpeza de bancadas das pias; limpeza do piso; descongelamento de manteiga; lavagem de latas de alimentos (no caso, milho); e lavagem de feijão.
} 
Na mesma linha de escopo, está a "Agenda Global Hospitais Verdes e Saudáveis", proposta do Saúde Sem Dano (2011), coalizão internacional de hospitais e sistemas de saúde além de sindicatos e organizações ambientalistas, e que indicam várias ações para que essas organizações, grandes consumidores de água tratada e que tendem a elevado consumo (por conta da demanda populacional consideravelmente alta) possam promover a saúde pública reduzindo o consumo dos recursos naturais e a emissão de resíduos poluentes.

$\mathrm{O}$ atendimento aos pacientes deve, em primeiro lugar, não causar dano aos mesmos e aos colaboradores, logo a preocupação de todos os Estabelecimentos de Assistência à Saúde (EAS) envolve as condições sanitárias de atendimento, higienização das instalações e essencialmente a não contaminação através da água. Consequentemente, a Cozinha, tida como uma das áreas críticas ${ }^{3}$ de um hospital (FIORENTINI et al., p. 23, 1995), deve se atentar para todos os condicionantes que implicam no fornecimento da alimentação correta e consequentemente na segurança dos trabalhadores envolvidos.

Diante do exposto, o objetivo geral deste estudo é analisar os riscos ocupacionais no ambiente de uma UAN hospitalar com enfoque nas atividades que se utilizam de água em maior quantidade. Os objetivos específicos: a) Identificar os riscos ocupacionais utilizando-se da técnica de Análise Preliminar de Riscos (APR) ocupacional e b) Identificar os riscos relacionados ao uso da água.

\section{MATERIAIS E MÉTODOS}

Este artigo trata de uma análise qualitativa e descritiva, que de forma exploratória se utilizou de visita in loco para observar a qualidade do ambiente e da execução das tarefas, além da pesquisa teórica referente à caracterização funcional de UAN hospitalar, aos riscos e ocorrências de acidentes e doenças (e suas implicações) e gestão e uso racional da água nesse ambiente de trabalho.

O objeto desse estudo é a Cozinha do Hospital Universitário Júlio Müller (HUJMUFMT - EBSERH), na cidade de Cuiabá-MT, com área de aproximadamente $175,80 \mathrm{~m}^{2}$ (desconsiderando área do refeitório, despensas, administrativo e câmaras frias), com um quadro de 41 funcionários de uma empresa terceirizada. Trabalham em três turnos, na seguinte escala: dois funcionários (administrativos) em escala 5x2 (dias de trabalho $\mathrm{x}$ dias de folga); cinco funcionários em escala $6 \times 1$ e duas equipes de plantão com 17 funcionários (12 atuam no período diurno e cinco no noturno) em escala de 12 x 36h. Servem em média 420 refeições diárias, além do café da manhã e lanche da tarde.

Como método de identificação de perigos, avaliação de riscos e determinação de medidas de controle, usou-se as etapas previstas na OSHAS 18001:2007 (BSI, 2007), a seguir descritas:

a) Atividades de rotina e não-rotina;

b) Atividades de todas as pessoas que tenham acesso aos locais de trabalho (incluindo subcontratados e visitantes);

c) Comportamento humano, capacidades e outros fatores humanos;

d) Perigos identificados originados fora dos locais de trabalho e capazes de afetar a segurança e a saúde de pessoas sob controle da organização no local de trabalho;

e) Perigos criados na vizinhança do local de trabalho por atividades relacionadas com o trabalho sob o controle da organização;

\footnotetext{
3 Áreas Críticas - são aquelas onde existe o risco aumentado de transmissão de infecção, onde se realizam procedimentos de risco ou onde se encontram pacientes com seu sistema imunológico deprimido.
} 
f) Infraestruturas, equipamentos e materiais nos locais de trabalho, quer sejam fornecidos pela organização quer por terceiros;

g) Alterações ou alterações propostas na organização, nas suas atividades ou materiais;

h) Modificações do sistema de gestão da SST, incluindo alterações temporárias e os seus impactos nas operações, processos e atividades;

i) Quaisquer obrigações legais aplicáveis relacionadas com a avaliação de riscos e com a implementação das medidas de controle necessárias;

j) A concepção das áreas de trabalho, processos, instalações, máquinas e equipamentos, procedimentos operacionais e organização do trabalho, incluindo a sua adaptação ás capacidades humanas. (OSHAS 18001:2007, item 4.3, subitem 4.3.1)

Os itens apresentados acima se relacionam com os apontados na NR 09, item 9.3.3, referente ao que deve ser aplicado na fase de reconhecimento dos riscos ambientais (BRASIL, 1978). A Análise Preliminar de Riscos, como um todo, consiste em uma avaliação prévia dos fatores de riscos evidentes e envolvidos em todas as etapas de execução de um determinado trabalho. Inclui-se a caracterização dos agentes causadores e consequentes efeitos, possibilitando numa próxima etapa a aplicação de medidas preventivas e mitigadoras, alertando para o nível de tolerância dos riscos, principalmente nos que são consequências de condições físicas inadequadas, ausência de equipamentos de proteção coletiva (ou, em último caso, individual). Consideram-se, também, os fatores organizacionais que contribuem para falhas humanas, pois mesmo que a tecnologia e mecanização atuem na maioria dos processos, a saúde e segurança do trabalhador é o foco.

\section{RESULTADOS/ DISCUSSÕES}

Dentro do processo produtivo, foram selecionados cargos e funções nos quais as atividades são mais impactadas pelo uso da água, seja pela quantidade utilizada, pelo tempo envolvido ou pela influência na questão de contaminação. As Copeiras, num total de 14 (cinco atuando das $7 \mathrm{~h}$ às $19 \mathrm{~h}$ e duas das $19 \mathrm{~h}$ às $7 \mathrm{~h}$ ), são as que mais circulam entre o hospital e a Cozinha, pois distribuem as refeições, auxiliam na montagem das mesmas (incluindo a salada) além de higienizarem bandejas e utensílios dos pacientes (Figura 1) e dos usuários do refeitório.

Figura 1- a) Copeiras na área de hortifrúti e Cozinheira de Carnes e b) Copeira na área de Higienização de Utensílios dos Pacientes

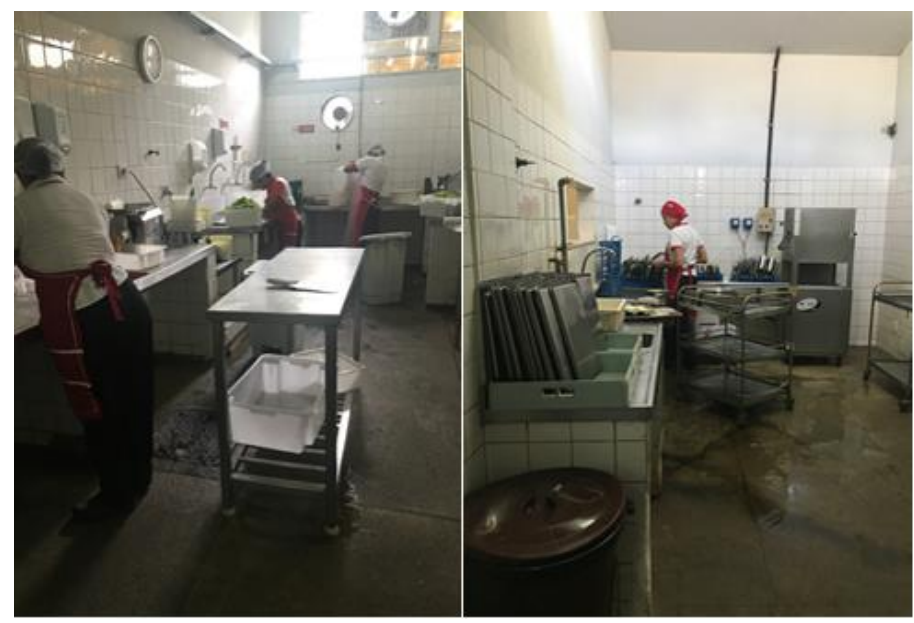

a)

b) 
Os Cozinheiros e seus Auxiliares (total de 10), responsáveis por parte do pré-preparo e cocção, lidam com a água diretamente ao fazerem a limpeza das bancadas e demais equipamentos ao final de cada preparo. É a função de maior permanência no ambiente e que mais impacta nas condições ambientais da Cozinha. A Cozinheira de Carnes, que trabalha das $07 \mathrm{~h}$ às $15 \mathrm{~h} 20 \mathrm{~min}$, seis dias por semana, trata do corte e preparo das carnes e opera em um dos principais pontos quanto à possível contaminação, visto que a forma de descongelamento interfere na qualidade do alimento (Figura 2).

Figura 2 - a) Cozinheiro Geral, b) Cozinheira Dietética e c) Cozinheira de Carnes

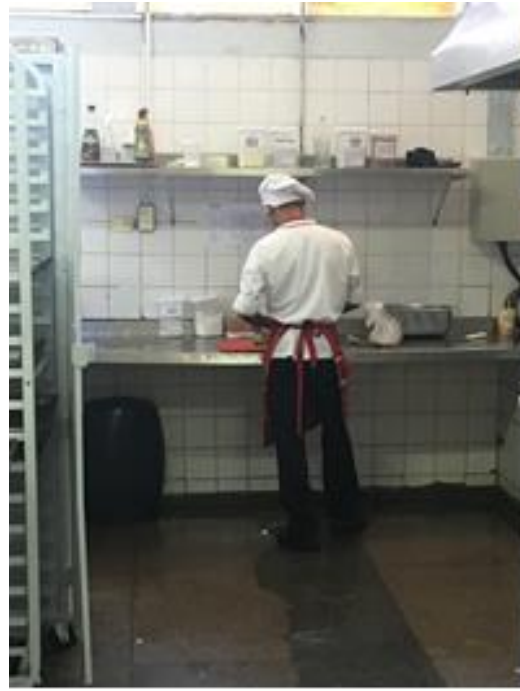

a)

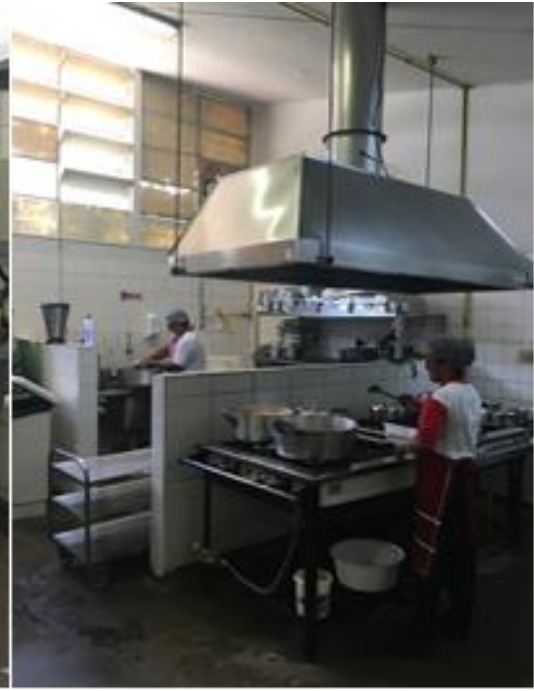

b)

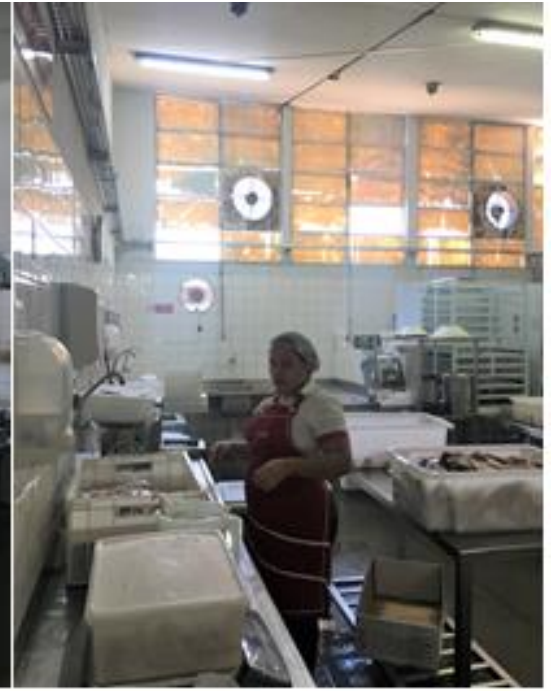

c)

A Auxiliar do Café trabalha seis dias por semana (07h às $15 \mathrm{~h} 20 \mathrm{~min})$ e deve se atentar para as quantidades indicadas, higienizar a bancada ou local para esse preparo além dos cuidados com o equipamento. O Auxiliar de Serviços Gerais (labora das 09h às 17h20min, seis dias por semana) realiza qualquer atividade referente ao auxilio no pré-preparo e, neste caso, é responsável pela lavagem e higienização dos utensílios e panelas usados no preparo e cocção dos alimentos (Figura 3).

Figura 3 - a) Auxiliar do Café e b) Auxiliar de Serviços Gerais

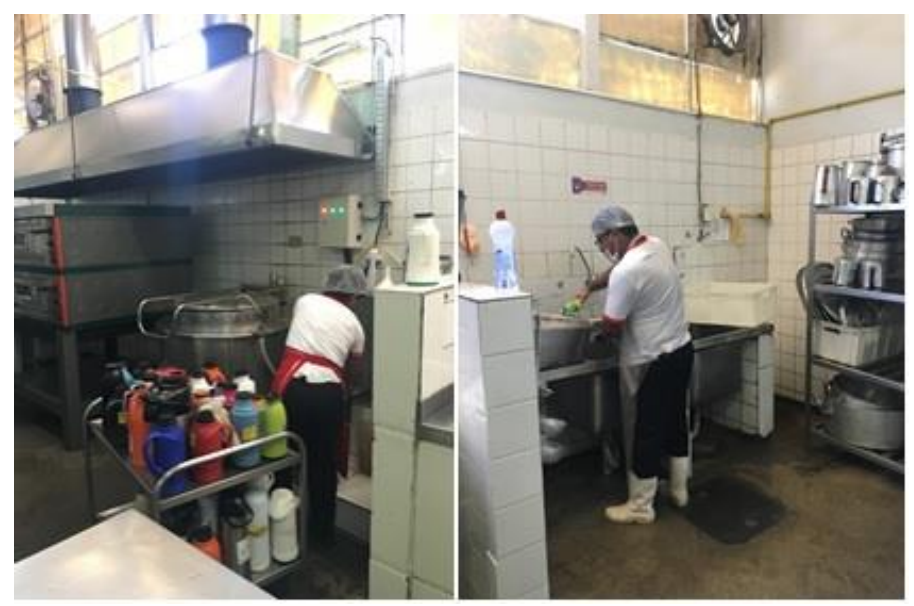

a)

b)

Nos $113,13 \mathrm{~m}^{2}$ de área, a Cozinha do HUJM-UFMT (Figura 4) possui a área das carnes (uma pia), saladas/hortifrúti (três pias), bancada de apoio para a área da cocção (sem pia), 
sobremesas (uma pia), higienização de utensílios e panelas (duas pias), área da dietética (uma pia) e bancadas móveis de apoio (Figura 5). Interligada está a área de higienização dos utensílios dos pacientes $\left(17,65 \mathrm{~m}^{2}\right)$ com duas pias mais uma lava-louças. A área de higienização dos utensílios do refeitório $\left(8,64 \mathrm{~m}^{2}\right)$ tem uma pia mais uma lava-louças e é separada, próxima ao buffet.

Figura 4 - Layout da Cozinha HUJM-UFMT

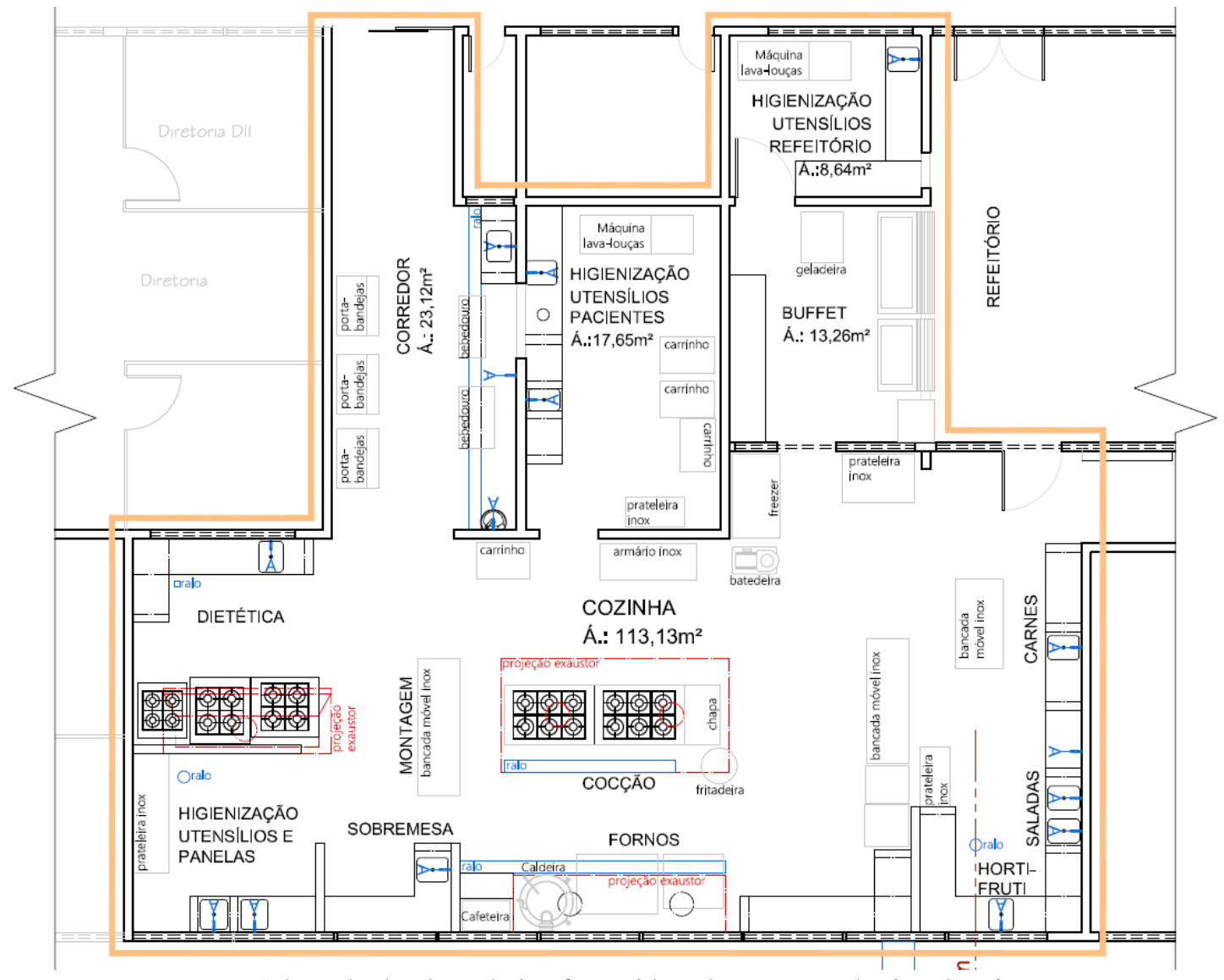

Fonte: Adaptado da planta baixa fornecida pela FN Engenharia e Serviços.

Figura 5- Vista da Cozinha a partir da área de carnes

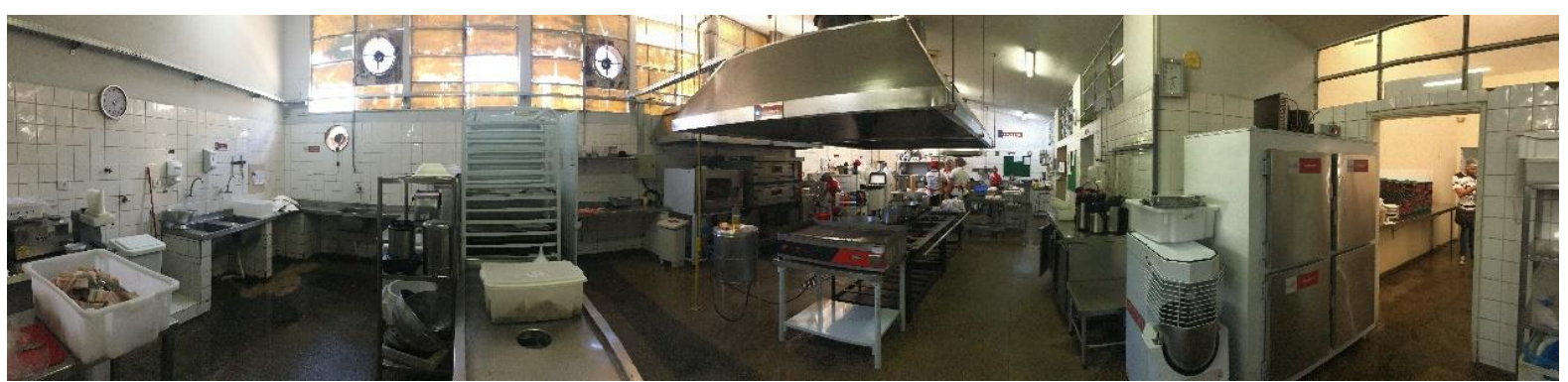

Entendendo que o planejamento arquitetônico contribui para a correta operacionalização da Cozinha, averiguou-se no ambiente alguns aspectos construtivos que se encontram fora das recomendações da ANVISA, favorecendo a proliferação de fungos e outros vetores por conta da umidade e calor constante. Citam-se como exemplos, o piso, do tipo granilite, sem o acabamento polido, têm diversos "remendos", desníveis entre áreas, com caimentos não favoráveis para os ralos, facilitando o acúmulo de águas residuais das diversas atividades. Em algumas das áreas, existem tampas que se acredita ser da caixa de gordura, 
porém durante as visitas não foi possível identificá-las e os funcionários não tinham conhecimento a respeito (Figura 6). Essas caixas devem ser localizadas fora da área de preparação, de acordo com a Resolução-RDC N ${ }^{\circ} 216$, de 15 de setembro de 2004 (BRASIL, 2014), pois suas frestas podem ser veículos de contaminação ou trânsito de vetores e insetos.

Figura 6 - a) Área de Preparo das Sobremesas e b) Área de Higienização dos utensílios dos Pacientes.

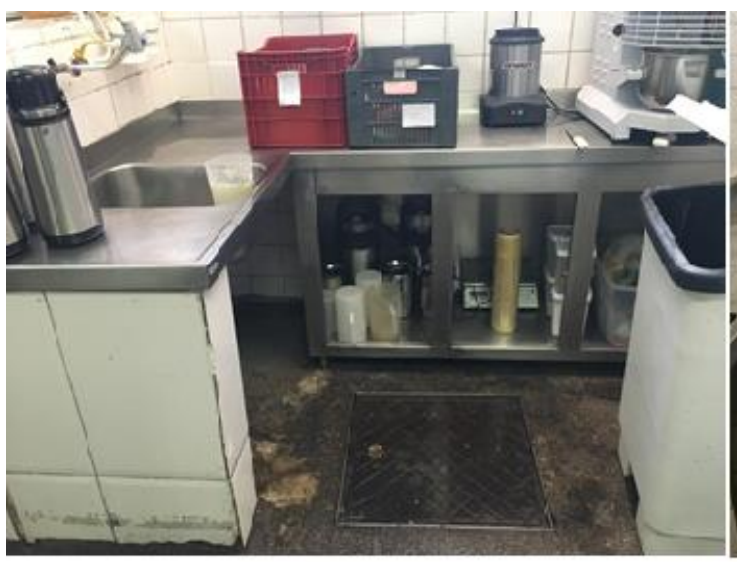

a)

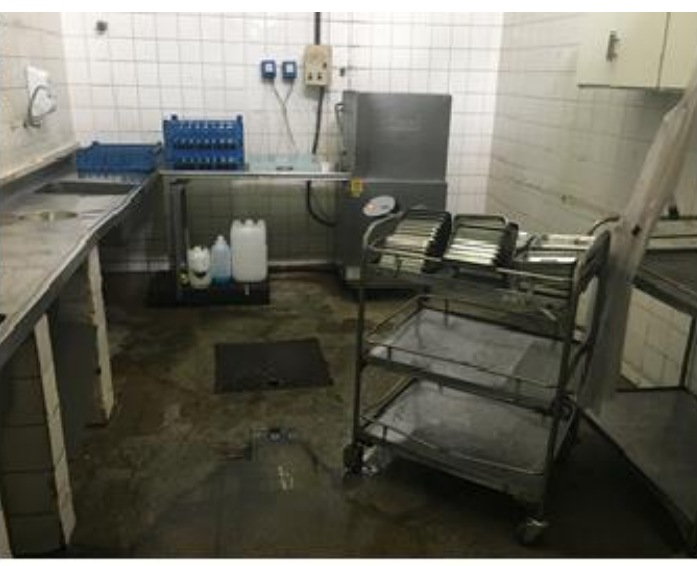

b)

Os azulejos, cerâmicos e de fácil lavagem, revestem as paredes até a altura de 2,30m e a base das bancadas (essas com o tampo em inox). Algumas dessas bases, principalmente nas áreas de higienizações de utensílios, estão com suas quinas quebradas, ajudando no acúmulo de poeiras, e possíveis acidentes envolvendo cortes e raspões.

Causando maior interferência no conforto térmico, e interligado com o sistema de proteção contra incêndio, está o sistema de exaustão. Perceberam-se diferenças de sensação térmica das áreas de pré-preparo e as áreas de cocção, claramente influenciadas pelo uso de seus respectivos equipamentos, mas que deveriam ser reduzidas pela exaustão, presente na área dos fogões e fornos e pelos exaustores/ventiladores (esses em condições precárias) nas janelas. De acordo com a NBR 14518 (ABNT, 2000), os equipamentos identificados na Cozinha são de classificação moderada em relação à produção de vapores de óleo e/ou partículas de gordura, e pelo tipo da edificação em que se encontra, exige-se sistema fixo de extinção de incêndio (proteção passiva), tomadas elétricas instaladas fora do fluxo gasoso (atenta-se para a fritadeira e chapa ligadas à tomada extensora enrolada no encanamento de gás) entre outros itens, como damper corta-fogo. Além desses pontos, não foram contemplados itens primordiais como iluminação e sinalização de emergência, extintores apropriados, portas corta-fogo entre a Cozinha e o corredor interno do hospital (Figura 7).

Figura 7 - Vista da Cozinha a partir da bancada de montagem

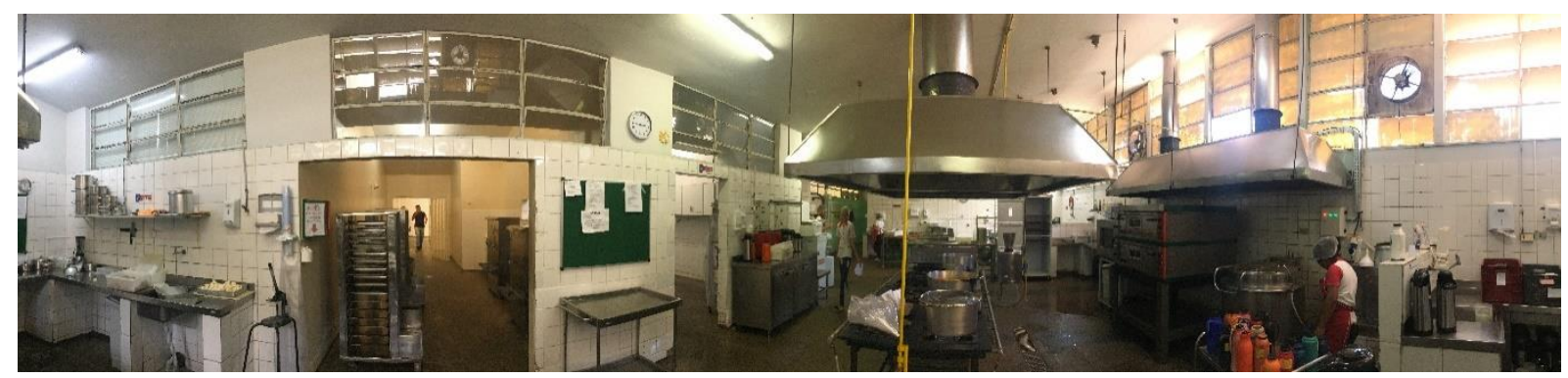

A execução da APR permitiu identificar de forma qualitativa que, no tocante ao conforto luminoso, ocorre insuficiência de luz natural em alguns pontos, que deveriam ser complementados pela luz artificial durante o dia. A área de cocção foi a mais prejudicada, visto que os exaustores provocam sombra pela sua dimensão e o fato da bancada estar 
embaixo das janelas (do tipo basculante e que foram pintadas por conta da insolação). A mesma situação pode ser notada também na higienização de utensílios dos pacientes e do refeitório. No período diurno, em caso de insolação mais forte, não se pode perceber, mas durante a noite, as lâmpadas atuam em quantidade e luminosidade insuficiente.

No desenvolvimento laboral da Cozinha, o envolvimento da água se dá por meio das atividades de preparo, utilizando diretamente nos alimentos, das atividades de higienização tanto dos alimentos quanto das louças e os utensílios de vários portes e em outras partes do sistema que a incorporam no produto final, como nos equipamentos de cocção, máquinas lava-louças, caldeiras, cafeteiras entre outros. A partir desse ponto, procurou-se entender quais as tarefas que facilitariam a separação dessas águas residuais, sendo destinadas a algum tratamento simplificado para reuso em atividades com fins não potáveis.

A limpeza das bancadas acontece diariamente, seja ao final dos turnos ou mesmo ao final das etapas de preparo. As áreas das higienizações, separadas fisicamente, têm um fluxo de funcionamento mais intenso após os horários das principais refeições, e pelas ações ali realizadas, repara-se uma considerável concentração de água empoçada nas mesmas. A posição da higienização dos utensílios e panelas, e pela sensação de umidade maior que o normal, parece intensificar as altas temperaturas das cocções geral e dietética, gerando assim uma "ilha de calor" que ocupa metade da Cozinha.

Ainda aplicando os preceitos da APR, observando-se o ambiente de trabalho, sob a ótica do aspecto comportamental, verificou-se que o desenvolvimento das tarefas ocorre de maneira apropriada, adotando os procedimentos de Boas Práticas sem maiores dificuldades, além daqueles encontrados no próprio ambiente de trabalho.

Então, assimilando as características do ambiente e sua influência no decorrer dos trabalhos, apresentam-se as Tabelas 1 e 2, a seguir, indicando os riscos ambientes e as possibilidades de reuso da água.

Tabela 1- Análise Preliminar de Riscos: Copeiras e Cozinheiros

\begin{tabular}{|c|c|c|c|}
\hline CARGO: & Copeira & FUNÇÃO: & Higienização \\
\hline ATIVIDADES: & \multicolumn{3}{|c|}{$\begin{array}{l}\text { Higienização utensílios pacientes e refeitório, bandejas das dietas, garrafas das clínicas/ } \\
\text { Organização dos carrinhos/ Lavagem leguminosas }\end{array}$} \\
\hline $\begin{array}{l}\text { PONTECIALIDADE } \\
\text { E DESTINAÇÃO }\end{array}$ & \multicolumn{3}{|c|}{$\begin{array}{l}\text { Lavagem das leguminosas/hortifruti/ dreno de saída das máquinas de lava-louças. } \\
\text { Destinação: estação de tratamento }\end{array}$} \\
\hline \multicolumn{4}{|c|}{ RISCOS AMBIENTAIS } \\
\hline FÍSICOS & \multicolumn{3}{|c|}{ Calor e umidade excessivos devido a ventilação deficiente e piso empoçado } \\
\hline QUÍMICOS & \multicolumn{3}{|c|}{$\begin{array}{l}\text { Detergentes e outros materiais de limpeza com conexões frágeis ligadas às máquinas de } \\
\text { lavar louças }\end{array}$} \\
\hline BIOLÓGICOS & \multicolumn{3}{|c|}{$\begin{array}{l}\text { Possível transmissão por parte do paciente, em relação a recolha das bandejas; fungos e } \\
\text { bactérias em limpeza com panos ou esponjas/acúmulo de fungos por umidade constante } \\
\text { do piso/ leguminosas e hortaliças contaminadas }\end{array}$} \\
\hline E.P.I & \multicolumn{3}{|c|}{ Luva de borracha/ touca/ avental/ sapato fechado de plástico } \\
\hline CARGO: & Cozinheiro Geral/Dietética e Auxiliares & FUNÇÃO: & Cocção \\
\hline ATIVIDADES: & \multicolumn{3}{|c|}{$\begin{array}{l}\text { Cocção mantimentos, caldos/ limpeza bancada de apoio/ limpeza fogão, fritadeira, chapa } \\
\text { e outros equipamentos elétricos }\end{array}$} \\
\hline $\begin{array}{l}\text { PONTECIALIDADE } \\
\text { E DESTINAÇÃO }\end{array}$ & \multicolumn{3}{|c|}{ Água (com sal e resíduos) da fritadeira. Destinação: estação de tratamento. } \\
\hline \multicolumn{4}{|c|}{ RISCOS AMBIENTAIS } \\
\hline FÍSICOS & \multicolumn{3}{|c|}{ Calor e umidade excessivos devido a ventilação deficiente e piso empoçado } \\
\hline QUÍMICOS & \multicolumn{3}{|c|}{ Não identificado } \\
\hline BIOLÓGICOS & \multicolumn{3}{|l|}{ Acúmulo de fungos por umidade constante do piso } \\
\hline E.P.I & \multicolumn{3}{|c|}{ Luva térmica/ touca/ avental/ sapato fechado de plástico } \\
\hline
\end{tabular}


CHRISTÓFFOLI, THAIZA; et al; Saúde, Segurança e Meio ambiente: Análise Preliminar de Riscos em atividades que fazem o uso da água em Cozinha Hospitalar. E\&S - Engineering and Science, 2018, 7:3.

Tabela 2- Análise Preliminar de Riscos: Cozinheira de Carnes, Auxiliar Café e Auxiliar Serviços Gerais

\begin{tabular}{|c|c|c|c|}
\hline CARGO: & Cozinheira de Carnes & FUNÇÃO: & Pré-preparo \\
\hline ATIVIDADES: & \multicolumn{3}{|c|}{ Descongelamento de carnes/ lavagem de carnes/ limpeza máquina de corte } \\
\hline $\begin{array}{l}\text { PONTECIALIDADE } \\
\text { E DESTINAÇÃO }\end{array}$ & \multicolumn{3}{|c|}{ Descongelamento de carnes ainda nas embalagens. Destinação: estação de tratamento } \\
\hline \multicolumn{4}{|c|}{ RISCOS AMBIENTAIS } \\
\hline FÍSICOS & \multicolumn{3}{|c|}{ Umidade excessiva devido a piso empoçado } \\
\hline QUÍMICOS & \multicolumn{3}{|c|}{ Não identificado } \\
\hline BIOLÓGICOS & \multicolumn{3}{|c|}{ Parasitas via água suja de sangue; acúmulo de fungos por umidade constante do piso } \\
\hline E.P.I & \multicolumn{3}{|c|}{$\begin{array}{l}\text { Luva de látex - manuseio/ luva de malha de aço - cortes/touca/avental/ sapato fechado } \\
\text { de plástico }\end{array}$} \\
\hline CARGO: & Auxiliar Café & FUNÇÃO: & Cocção \\
\hline ATIVIDADES: & \multicolumn{3}{|c|}{$\begin{array}{l}\text { Enchimento reservatório cafeteira/ enchimento garrafas térmicas/ higienização do local } \\
\text { de preparo do café/ higienização garrafas térmicas/ higienização cafeteira }\end{array}$} \\
\hline $\begin{array}{l}\text { PONTECIALIDADE } \\
\text { E DESTINAÇÃO }\end{array}$ & \multicolumn{3}{|c|}{$\begin{array}{l}\text { Higienização das garrafas térmicas/ higienização parte interna cafeteira. Destinação: } \\
\text { estação de tratamento }\end{array}$} \\
\hline \multicolumn{4}{|c|}{ RISCOS AMBIENTAIS } \\
\hline FÍSICOS & \multicolumn{3}{|c|}{$\begin{array}{l}\text { Calor e umidade excessivos devido à ventilação deficiente e piso empoçado. Risco de } \\
\text { acidente devido ao contato com o líquido quente provocando queimadura. }\end{array}$} \\
\hline QUÍMICOS & \multicolumn{3}{|c|}{ Não identificado } \\
\hline BIOLÓGICOS & \multicolumn{3}{|c|}{ Acúmulo de fungos por umidade constante do piso } \\
\hline E.P.I & \multicolumn{3}{|c|}{ Touca/ avental/ sapato fechado de plástico } \\
\hline CARGO: & Auxiliar Serviços Gerais & FUNÇÃO: & Higienização \\
\hline ATIVIDADES: & \multicolumn{3}{|c|}{ Lavagem de panelas e palafrões } \\
\hline $\begin{array}{l}\text { PONTECIALIDADE } \\
\text { E DESTINAÇÃO }\end{array}$ & \multicolumn{3}{|c|}{$\begin{array}{l}\text { Tanto a água de remoção quanto a de lavagem poderão conter materiais orgânicos, óleos } \\
\text { e sabões, mas podem ser utilizadas para fins não potáveis. Destinação: estação de } \\
\text { tratamento }\end{array}$} \\
\hline \multicolumn{4}{|c|}{ RISCOS AMBIENTAIS } \\
\hline FÍSICOS & \multicolumn{3}{|c|}{ Calor e umidade excessivos devido à ventilação deficiente e piso empoçado } \\
\hline QUÍMICOS & \multicolumn{3}{|c|}{ Manipulação direta com detergentes, sabões entre outros produtos de limpeza } \\
\hline BIOLÓGICOS & \multicolumn{3}{|c|}{ Acúmulo de fungos por umidade constante do piso } \\
\hline E.P.I & \multicolumn{3}{|c|}{ Luva de borracha/ touca/avental/ sapato fechado de plástico } \\
\hline
\end{tabular}

A APR permitiu identificar os riscos ocupacionais, tais como: queda ou tropeço por conta do piso irregular e água estagnada, fadiga visual devido à pouca iluminação e risco de choques elétricos e curto-circuito (devido às instalações elétricas em conduítes externos, especialmente as instalações das máquinas de lavar-louças, fritadeira, caldeira e cafeteira). Para as Copeiras, que lidam com as lava-louças, é preciso atenção ao risco de queimaduras por conta do vapor da máquina ou mesmo de respingo da água quente usada na higienização.

A água, elemento básico para a vida, é consequentemente essencial dentro de um hospital. Diversas atividades a envolvem direta ou indiretamente. Logo, sua contaminação pode se tornar um problema grave de saúde pública, seja na maneira como é captada, armazenada, distribuída, manipulada ou devolvida ao meio. Por meio da situação exposta, foi possível visualizar a maneira como a água vem sendo usada no trabalho na UAN hospitalar, onde se percebeu o atendimento as Boas Práticas preconizadas. No entanto, seu descarte carece de ser feito de forma mais responsável. Para tanto, um plano de gestão do uso da água pode ser construído com os colaboradores e implementado. 


\section{CONSIDERAÇÕES FINAIS}

Este estudo qualitativo buscou, dentro de uma UAN hospitalar, identificar os agentes ambientais com o objetivo de avaliar os riscos ocupacionais presentes em atividades que fazem maior uso da água, tanto quanto os possíveis riscos envolvendo a mesma, e assim propor ações mitigadoras para os problemas encontrados.

Diante do exposto, aponta-se como ação prioritária, mas que deve ser resolvida em médio prazo, em virtude da complexidade de execução, o tratamento do piso, substituindo-o por material de superfície mais lisa, impermeável e lavável - com a garantia de se manter antiderrapante, envolvendo assim o estudo de posição e dimensionamento dos ralos, colocando o caimento do piso para os mesmos. Os ralos devem ser sifonados e possuir dispositivo que facilite seu fechamento. Mister se faz também necessário a investigação mais detalhada sobre as tampas de caixas de inspeção, reposicionado as mesmas e se possível eliminando-as desse ambiente, devido ao alto risco de contaminação.

O segundo quesito é a exaustão, que envolve a questão preventiva do risco de incêndio, o auxílio na remoção de vapores e gorduras melhorando a circulação do ar dentro do ambiente. É necessário rever a manutenção preventiva, seu dimensionamento e, em último caso, o seu posicionamento, visto que a cocção e dietética formam uma concentração alta de calor e a localização da higienização dos utensílios parece impulsionar esse agente, além de "atravessar" erroneamente o fluxo desse setor. Como última questão do ponto de vista predial, além da manutenção das lâmpadas existentes, é preciso realocar os pontos de iluminação, principalmente nas áreas da cocção e do preparo de carnes, que atuam diretamente com objetos cortantes como facas, moedor de carnes, etc.

Perante essas condições, se faz relevante a elaboração de um mapa de riscos abrangendo as áreas não estudadas (administração, estoque), bem como a concepção de um Projeto de Prevenção e Combate ao Incêndio (ou revisão do que já deve existir para o Hospital), visto que os funcionários são prestadores de serviço terceirizados, mas a responsabilidade frente ao ambiente do trabalho é da Instituição.

Porém, antes de qualquer intervenção, é necessário um estudo preliminar da vazão diária do espaço, incluindo a identificação de possíveis pontos de vazamento nas pias, nas instalações sanitárias do setor, nos equipamentos que utilizam a água diretamente (é essencial que a manutenção preventiva da máquina lava-louças seja feita conforme planejado, evitando uso excessivo para atividades já programadas e calculadas) e então demonstrar a real viabilidade para implantação de um sistema de reuso.

Nessa análise, procuraram-se pontos de uso que pudessem favorecer a separação das águas com potencial de reuso, sem que intervissem ou se tornassem um agravante na execução dos procedimentos. A água residual da máquina de lavar louças, da fritadeira e dos demais equipamentos que as incorporam no produto final pode ser depositada por meio de tubulações diretamente para o reservatório. Já a água de lavagem e higienização de bancadas ou da limpeza das carnes, que devido ao processo de execução dessa atividade transborda dos limites das bancadas e escorre para o chão, não é passível de reuso, uma vez que se mistura com restos de resíduos dos alimentos, sangue, óleos e produtos de limpeza, podendo se tornar um fator de risco ambiental grave em caso reaproveitamento.

Demonstrou-se aqui, a avaliação dos riscos relacionados ao uso da água em um importante setor de uma edificação complexa como a de uma unidade hospitalar. A Cozinha apresenta uma diversidade de riscos abrangendo não somente os trabalhadores e pacientes, mas a população 'flutuante', como visitantes e outros eventuais prestadores de serviços. Portanto, a participação da alta gestão, bem como dos trabalhadores, se faz indispensável tanto frente aos riscos ocupacionais quanto aos riscos ambientais, pois representam uma 
CHRISTÓFFOLI, THAIZA; et al; Saúde, Segurança e Meio ambiente: Análise Preliminar de Riscos em atividades que fazem o uso da água em Cozinha Hospitalar. E\&S - Engineering and Science, 2018, 7:3.

instituição de saúde, e como tal, podem e devem agir em defesa da saúde e segurança do trabalho assim como do meio ambiente.

\section{AGRADECIMENTOS}

À Fundação de Apoio à Pesquisa do Distrito Federal - FAP-DF, pelo apoio financeiro ao projeto de pesquisa intitulado Eficiência Hídrica em Unidades de Saúde: Diagnóstico e Soluções.

\section{APROVAÇÕES}

Projeto de pesquisa aprovado no Comitê de Ética em Pesquisa do Hospital Julio Muller, CAAE 71555417.0.0000.5541, parecer 2.304.452, datado de 28 de Setembro de 2017.

\section{REFERÊNCIAS}

ASSOCIAÇÃO BRASILEIRA DAS EMPRESAS DE REFEIÇÕES COLETIVAS (ABERC). Manual ABERC de Práticas de Elaboração e Serviço de Refeições para Coletividades. 10 ed. São Paulo, 2013. 51-57p.

ASSOCIAÇÃO BRASILEIRA DE NORMAS TÉCNICAS (ABNT). NBR 14518 - Sistemas de ventilação para cozinhas profissionais. Rio de Janeiro, 2000. 25p.

ARAÚJO, E. M. G. de Análise da Organização e das Condições de trabalho em uma unidade de alimentação e nutrição em relação ao desempenho e à satisfação no trabalho: um estudo de caso. 2010. 102p. Dissertação (Mestre em Sistema de Gestão. Área de concentração: Segurança do Trabalho) - Centro Tecnológico - Universidade Federal Fluminense, Niterói, 2010.

BRASIL. Ministério da Saúde. Agência Nacional de Vigilância Sanitária - ANVISA. Resolução-RDC $\mathrm{n}^{\circ}$ 50, de 21 de fevereiro de 2002. Dispões sobre o Regulamento Técnico para planejamento, programação, elaboração e avaliação de projetos físicos de estabelecimentos assistências de saúde. Diário Oficial da União; Brasília, DF, 22 de fevereiro de 2004.

Ministério da Saúde. Agência Nacional de Vigilância Sanitária - ANVISA. Resolução-RDC $N^{\circ} 216$, de 15 de setembro de 2004. Dispõe sobre Regulamento Técnico de Boas Práticas para Serviços de Alimentação. Diário Oficial da União; Brasília, DF, 16 de setembro de 2004.

Ministério do Trabalho. Portaria MTb $\mathrm{n}^{\circ}$ 3.214. Norma Regulamentadora 9 Programa de Prevenção de Riscos Ambientais, de 08 de junho de 1978. Diário Oficial da União, 06 jul. 1978.

Ministério do Trabalho e Emprego. Portaria GM n ${ }^{\circ}$ 485. Norma Regulamentadora 32 - Segurança e Saúde no Trabalho em Serviços de Saúde, de 11 de novembro de 2005. Diário Oficial da União, 16 nov. 2005.

BRASILEIRO M.E., RODRIGUES, L.F., NAZARENO, N.F., OLIVEIRA, R. Protocolo de prevenção de riscos ambientais em cozinhas industriais. Revista Eletrônica de Enfermagem 
CHRISTÓFFOLI, THAIZA; et al; Saúde, Segurança e Meio ambiente: Análise Preliminar de Riscos em atividades que fazem o uso da água em Cozinha Hospitalar. E\&S - Engineering and Science, 2018, 7:3.

do Centro de Estudos de Enfermagem e Nutrição [serial on-line], v.2, n.2, p1-13, 2013. Disponível

em: <http://www.cpgls.pucgoias.edu.br/8mostra/Artigos/SAUDE\%20E\%20BIOLOGICAS/Protoc olo $\% 20 \mathrm{de} \% 20$ preven $\% \mathrm{C} 3 \% \mathrm{~A} 7 \% \mathrm{C} 3 \% \mathrm{~A} 3 \mathrm{o} \% 20 \mathrm{de} \% 20$ riscos $\% 20$ ambientais $\% 20 \mathrm{em} \% 20$ cozin has\%20industriais.pdf $>$. Acesso em: 18 out. 2018.

BRITISH STANDARDS INSTITUTION (BSI). Occupational Health and Safety Assessment Series (OHSAS) 18.001/2007 - Sistemas de gestão da segurança e da saúde do trabalho - $\quad$ Requisitos. Disponível em: <https://comum.rcaap.pt/bitstream/10400.26/7319/2/Anexo\%20I\%20OHSAS180012007_pt.p df>. Acesso em: 13 dez. 2017.

FIORENTINI, D.M.F.; LIMA, V.H. A.; KARMAN, J.B. Arquitetura na Prevenção de Infecção Hospitalar. Brasília: Ministério da Saúde, Secretaria de Assistência à Saúde. Série Saúde \& Tecnologia - Textos de Apoio à Programação Física dos Estabelecimentos Assistenciais de Saúde, 1995. 76 p.

INTERNATIONAL ORGANIZATION FOR STANDARDIZATION (ISO). DIS-ISO 45001:2016. Gestão de Saúde e Segurança Ocupacional - Requisitos com orientações para uso. Disponível em: <https://pt.scribd.com/document/340195794/DIS-ISO-45001-2016Comentada-pdf>. Acesso em: 01 fev. 2018.

ISOSAKI, M.; CARDOSO, E.; GLINA, D. M. R.; ALVES, A. C. D. C.; ROCHA, L. E. Prevalência de sintomas osteomusculares entre trabalhadores de um Serviço de Nutrição Hospitalar em São Paulo, SP. Revista Brasileira de Saúde Ocupacional, v.36, n.124, p.238246, 2011. Fundação Jorge Duprat Figueiredo de Segurança e Medicina do Trabalho. Disponível em: <http://www.redalyc.org/pdf/1005/100521304007.pdf >. Acesso em: 31 jan. 2018.

KAMINAGAKURA, C. Avaliação dos principais fatores intervenientes no consumo de água em Unidades De Alimentação e Nutrição como subsídio para o seu uso racional. 159f. 2005. Dissertação (Mestre em Engenharia de Edificações e Saneamento) Centro de Tecnologia e Urbanismo, Universidade Estadual de Londrina, Londrina, 2005.

LEHMKUHL, R. S. Biossegurança em Cozinhas Hospitalares. 1998. 78p. Especialização (Gestão Hospitalar) Centro de Desenvolvimento de Recursos Humanos da Saúde, Universidade Federal de Santa Catarina e Secretaria de Estado da Saúde, Florianópolis, 1998.

LIMA, L. C. Uso doméstico da água em hospitais: estudo de caso do hospital das clinicas da UNICAMP. 2007. 188f. Dissertação (Mestre em Engenharia Civil, na área de concentração de Edificações) - Faculdade de Engenharia Civil, Arquitetura e Urbanismo da Universidade Estadual de Campinas, Campinas: [s.n.], 2007.

NAÇÕES UNIDAS NO BRASIL. ONUBR. Objetivos do Desenvolvimento Sustentável. Objetivo 6 - Água Potável e Sustentável. Disponível em: $<$ https://nacoesunidas.org/pos2015/ods6/>. Acesso em 18 jan. 2018.

PONTE A. S., RIBAS M. A. M., PINTO V. M. A importância do mapa de risco para a prevenção de acidentes de trabalho em cozinhas/copas de hospitais do interior do Rio Grande do Sul/RS. Saúde (Santa Maria), v. 40, n. 2, p.123-130, 2014. Disponível em: <https://periodicos.ufsm.br/revistasaude/article/view/12549>. Acesso em: 18 jan. 2018. 
CHRISTÓFFOLI, THAIZA; et al; Saúde, Segurança e Meio ambiente: Análise Preliminar de Riscos em atividades que fazem o uso da água em Cozinha Hospitalar. E\&S - Engineering and Science, 2018, 7:3.

SAÚDE SEM DANO. Agenda Global Hospitais Verdes e Saudáveis. Disponível em: <https://www.greenhospitals.net/wp-content/uploads/2016/07/GGHHA-Portugese.pdf>.

Acesso em 10 jan. 2018.

THE WAIT FOR ISO 45001 IS OVER. Disponível em: $<$ https://ohsonline.com/articles/2018/02/01/the-wait-for-iso-45001-is-over.aspx>. Acesso em: 01 fev. 2018. 